\title{
Dynamics of Interfacial Charge Transfer States and Carriers Separation in Dye-Sensitized Solar Cells: A Time-Resolved Terahertz Spectroscopy Study
}

\author{
Jan C. Brauer, Arianna Marchioro, Arun A. Paraecattil, Ahmad A. Oskouei, and Jacques-E. Moser* \\ Photochemical Dynamics Group, Institute of Chemical Sciences and Engineering, and Lausanne Centre for Ultrafast Science \\ (LACUS), Ecole Polytechnique Fédérale de Lausanne, CH-1015 Lausanne, Switzerland
}

\section{Supporting Information}

\begin{abstract}
Electron injection from a photoexcited molecular sensitizer into a wide-bandgap semiconductor is the primary step toward charge separation in dye-sensitized solar cells (DSSCs). According to the current understanding of DSSCs functioning mechanism, charges are separated directly during this primary electron transfer process, yielding hot conduction band electrons in the semiconductor and positive holes localized on oxidized dye molecules at the surface. Comparing results of ultrafast transient absorption and time-resolved terahertz measurements, we show here that intermediate interfacial charge transfer states (CTSs) are rather formed upon ultrafast injection from photoexcited $\mathrm{Ru}(\mathrm{II})-$ bipyridyl dye-sensitizer molecules into mesoporous $\mathrm{TiO}_{2}$ films. Formation

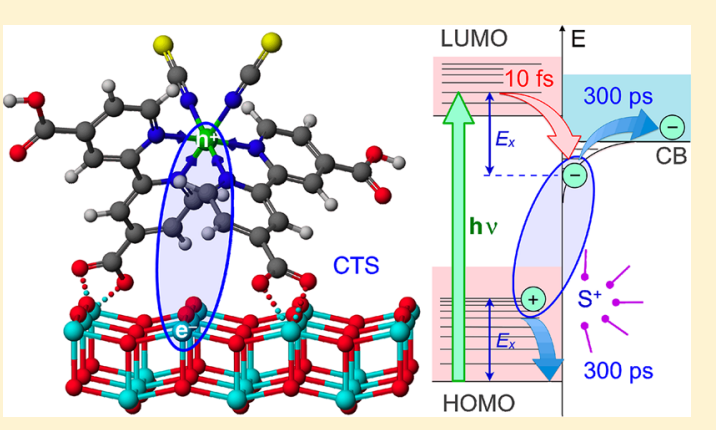
and dissociation of these CTSs were found to strongly depend on their ionic environment and excess excitation energy. This finding establishes a new mechanism for charge separation in DSSCs. It also offers a rationale for the effect of electrolyte composition in liquid-based devices and of ion doping in solid-state solar cells under working conditions.
\end{abstract}

\section{INTRODUCTION}

Dye-sensitized solar cells (DSSCs) present a promising way in the quest for cost-effective photovoltaics, owing in particular to their ease of fabrication, high efficiency under low-density illumination, and customizable aesthetics. DSSCs belong to the family of hybrid donor-acceptor bulk heterojunction photovoltaic converter systems. They are based on a mesoporous $\mathrm{TiO}_{2}$ film, constituting the photoanode, onto which a monolayer of a molecular sensitizer is adsorbed. The pores of the dyed nanocrystalline film are filled with either a liquid redox-active electrolyte or a solid-state organic hole transport material. $^{1-4}$

In the absence of a built-in electric field at the interface able to separate photogenerated electron-hole pairs, light-induced charge separation in bulk heterojunction cells relies on the kinetic competition between several forward electron transfer, charge transport, and recombination processes. ${ }^{4-6}$ Hence, a detailed investigation of the dynamics of interfacial charge transfer is essential for the understanding of the device functioning mechanism. The kinetics of electron injection from photoexcited heteroleptic $\mathrm{Ru}(\mathrm{II})$ bipyridyl dyes into titanium dioxide $\left(\mathrm{TiO}_{2}\right)$ semiconductor nanoparticles have been extensively studied. Most of the reports describe the kinetics of the primary light-induced, interfacial charge transfer process as being multiexponential and different rationales for the observed kinetic heterogeneity have been proposed. ${ }^{7-12}$ Although a majority of studies report ultrafast electron injection taking place within a sub-100 fs time scale, recent measurements carried out by using transient IR spectroscopy in the presence of an electrolyte suggest that charge separation in $\mathrm{Ru}$ (II) complex dye-sensitized solar cells might be much slower. ${ }^{13,14}$ Results obtained here and their interpretation reconcile these apparently contradicting observations. While initial femtosecond photoinduced electron injection is confirmed, actual charge separation to yield free mobile carriers is shown to be hindered by electron trapping in charge transfer states, whose dissociation in the presence of an electrolyte or in contact with a hole transport material can extend over hundreds of picoseconds.

\section{EXPERIMENTAL SECTION}

Ultrafast Time-Resolved Terahertz Spectroscopy Setup. $^{15}$ The initial pulsed laser beam $(\lambda=800 \mathrm{~nm}$ wavelength, $45 \mathrm{fs}$ pulse duration, $4.5 \mathrm{~mJ} /$ pulse energy, $1 \mathrm{kHz}$ repetition rate) provided by an amplified Ti:sapphire laser (Libra, Coherent) was split into different paths. Approximately $1.4 \mathrm{~mJ} /$ pulse was used to pump a white light-seeded optical parametric amplifier (OPA) (OPerA Solo, Coherent), whose wavelength-tunable output constituted the optical pump to photogenerate carriers in the sample. At $590 \mathrm{~nm}$ pump wavelength, a typical energy of $8 \mu \mathrm{J} /$ pulse was used, corresponding to a maximum energy fluence at the sample of $200 \mu \mathrm{J} \mathrm{cm}^{-2} /$ pulse $\left(5.9 \times 10^{14}\right.$ photons $\mathrm{cm}^{-2} /$ pulse $)$. A second

Received: July 17, 2015

Revised: November 3, 2015

Published: November 4, 2015 
part of the beam $(0.9 \mathrm{~mJ} /$ pulse $)$ produced single cycle terahertz $(\mathrm{THz})$ pulses by optical rectification in a $1 \mathrm{~mm}$ thick $\mathrm{ZnTe}$ crystal. The $\mathrm{THz}$ beam was focused by parabolic gold mirrors on the sample and used as a probe. The transmitted $\mathrm{THz}$ pulses were detected in the time-domain through free space electrooptic sampling. A third part of the initial laser beam was used as gating beam and was guided over a delay line onto a $0.5 \mathrm{~mm}$ thick $\mathrm{ZnTe}$ detector crystal. Birefringence induced in the $\mathrm{ZnTe}$ crystal by the electric field associated with the transmitted $\mathrm{THz}$ radiation was converted into an intensity modulation using a quarter-wave plate and a Wollaston prism polarizer and finally detected by a pair of balanced photodiodes (Nirvana 2007, New Focus).

Femtosecond Transient Absorption Spectroscopy (TAS) Setup. ${ }^{16}$ An amplified Ti:sapphire femtosecond laser (CPA 2001, Clark-MXR) was used as a light source. The laser had a $1 \mathrm{kHz}$ repetition rate, with typical pulse energy of $950 \mu \mathrm{J}$ at a fundamental wavelength of $775 \mathrm{~nm}$ and pulse duration of 140 fs. Half the source intensity was used for pumping two noncollinear phase-matched OPAs (NOPA Plus, Clark MXR), allowing for the generation of monochromatic pump and probe beams. The probe two-stage NOPA allowed the generation of a near-IR beam, with $\lambda_{\text {probe }}=840 \mathrm{~nm}$. The spectral profile of the pulses was measured using a dual-channel CCD spectrometer (S2000, Ocean Optics). The output pulses of the NOPAs were compressed by SF10 prisms pairs down to sub-50 fs duration. The temporal profile of the pulses was determined using a portable autocorrelator (PulseCheck, A.P.E). The relative path length between the two beams was changed with a delay line, alternatively on the pump or on the probe pulse. The motorized translation stage (M531 PD, Physik Instrumente) allowed time steps of $10 \mathrm{fs}$ and generated delays up to $2 \mathrm{~ns}$. The pump beam was chopped at half the repetition frequency of the pulsed laser source. The change in transmittance of the sample, i.e., change in intensity of the probe beam, was measured by a photodiode placed after the sample and protected by cutoff filters to avoid any scattered light from the pump. The lowamplitude signal was extracted by a lock-in amplifier (SR-830, Stanford Research) referenced to the chopper. To ensure isotropic excitation of the sample, the pump polarization was set at the magic angle $\left(54.7^{\circ}\right)$ relative to the probe pulse with a $\lambda / 2$ waveplate. A lens allowed tuning the size of the pump beam before the sample to both decrease the fluence and allow for complete overlap of the probed spot area. The energy fluence on the sample was limited to a maximum of $230 \mu \mathrm{J}$ $\mathrm{cm}^{-2} /$ pulse $\left(6.8 \times 10^{14}\right.$ photons $\mathrm{cm}^{-2} /$ pulse $)$. Temporal overlap between the pump and probe pulses at the sample position was measured with a Kerr gating technique and gave a typical instrument response function (IRF) of $120 \mathrm{fs}$.

Sample Preparation. Liquid Electrolyte Samples. $10.2 \mu \mathrm{m}$ thick $\mathrm{TiO}_{2}$ films were prepared by screen-printing a $\mathrm{TiO}_{2}$ paste on a quartz substrate and sintering at $500{ }^{\circ} \mathrm{C}$, according to a previously described procedure. ${ }^{17}$ To increase adhesion of the film onto the substrate, a compact $\mathrm{TiO}_{2}$ underlayer was applied by spray pyrolysis. The paste consisted of $\mathrm{TiO}_{2}$ particles with an average diameter of $\sim 20 \mathrm{~nm}$ dispersed in aqueous ethyl cellulose. The procedure yielded mesoporous transparent films with an average pore diameter of $\sim 26 \mathrm{~nm}$ and a porosity of 0.68. $\left(\mathrm{Bu}_{4} \mathrm{~N}\right)_{2}\left[\right.$ cis-Ru $\left.{ }^{\mathrm{II}}(\mathrm{Hdcbpy})(\mathrm{NCS})_{2}\right](\mathrm{N} 719)^{18}$ was used as dye sensitizer. Derivatization of mesoporous $\mathrm{TiO}_{2}$ surface was achieved by immersing films overnight in a $0.4 \mathrm{mM}$ N719 solution in ethanol. The solvent or the electrolyte was applied onto the sample just before measurement by placing a quartz cover slide on the sample and by sucking the solution by capillarity between the dye-sensitized $\mathrm{TiO}_{2}$ film and the cover slide.

Solid-State Samples. Samples consisted of $2.3 \mu \mathrm{m}$ thick $\mathrm{TiO}_{2}$ films made by screen-printing a paste, whose particle size and ethyl cellulose content were optimized for solid-state DSSCs. ${ }^{19}$ The obtained transparent films contained $22 \mathrm{~nm}$ diameter particles and were characterized by an average pore diameter of $28 \mathrm{~nm}$ and a porosity of 0.671 . Z907 dye (cisbis(isothiocyanato) (2,2' -bipyridyl-4,4' -dicarboxylato $)\left(4,4^{\prime}\right.$-dinonyl-2'-bipyridyl) $\left.\mathrm{Ru}^{\mathrm{II}}\right)$ was used as a sensitizer and adsorbed onto the film as for the liquid electrolyte samples. ${ }^{18}$ The holeconducting material 2,2',7,7'-tetrakis ( N,N-di-4-methoxyphenylamino)-9,9'-spirobifluorene (spiro-MeOTAD) was applied onto the films by spin-coating: $40 \mu \mathrm{L}$ of spiro-MeOTAD solution was deposited onto the sensitized substrates and allowed to infiltrate for $30 \mathrm{~s}$ in order to maximize the penetration of the HTM prior to spin-coating for $30 \mathrm{~s}$ at 2000 rpm. Three different solutions were prepared: Solution 1 contained only spiro-MeOTAD, solution 2 spiro-MeOTAD and $\mathrm{Li}^{+}$, and solution 3 spiro-MeOTAD and 4-tert-butylpyridine (tBP). $72 \mathrm{mg}$ of spiro-MeOTAD was dissolved in $400 \mu \mathrm{L}$ of chlorobenzene by heating the solution at $60{ }^{\circ} \mathrm{C}$ for $20 \mathrm{~min}$. In solution $2,15 \mu \mathrm{L}$ of a $\mathrm{Li}^{+}$solution, obtained by dissolving 17 mg of LiTFSI in $100 \mu \mathrm{L}$ of MeCN, was added to the HTM solution. Solution 3 was obtained by adding $7 \mu \mathrm{L}$ of solid tBP to solution 1. Preparation of all solutions and spin-coating were carried out in a dry glovebox in the absence of oxygen. After preparation, samples were stored in the glovebox in the dark until they were measured.

\section{RESULTS}

A combination of ultrafast vis/NIR transient absorption and time-resolved $\mathrm{THz}$ spectroscopies was applied to scrutinize the details of interfacial photoinduced charge separation in liquid electrolyte- and solid-state hole transport material-based DSSCs. An efficient molecular redox dye-sensitizer (S), $\left(\mathrm{Bu}_{4} \mathrm{~N}\right)_{2}\left[\right.$ cis-Ru $\left.{ }^{\mathrm{II}}(\mathrm{Hdcbpy})(\mathrm{NCS})_{2}\right] \quad(\mathrm{N} 719)$, was adsorbed onto the surface of nanocrystalline $\mathrm{TiO}_{2}$ transparent films deposited on fused silica plates. The films had their pores filled either with pure acetonitrile $\left(\mathrm{CH}_{3} \mathrm{CN}\right)$ solvent or with an electrolyte used in efficient DSSCs and containing $0.6 \mathrm{~mol} \mathrm{~L}^{-1}$ iodide $\left(\mathrm{I}^{-}\right), 0.1 \mathrm{~mol} \mathrm{~L}^{-1}$ triiodide $\left(\mathrm{I}_{3}^{-}\right), 0.6 \mathrm{~mol} \mathrm{~L}^{-1} 1,3-$ dimethylimidazolium $\left(\mathrm{DMI}^{+}\right), 0.1 \mathrm{~mol} \mathrm{~L} \mathrm{~L}^{-1}$ lithium cations $\left(\mathrm{Li}^{+}\right)$, and $0.6 \mathrm{~mol} \mathrm{~L}^{-1}$ 4-tert-butylpyridine (tBP) dissolved in acetonitrile. ${ }^{20}$ Upon femtosecond laser pulse excitation of the samples, optical absorption of the oxidized state of the dye $\left(\mathrm{S}^{+}\right)$ was promptly observed in the NIR spectral domain with a rise time $<50$ fs. The optical transient absorbance at $\lambda=840 \mathrm{~nm}$ signal allowed monitoring directly the kinetics of photoinduced electron injection from the MLCT electronic excited state of the dye $\left(S^{*}\right)$ into the conduction band of titanium dioxide: $S \mid$ $\mathrm{TiO}_{2}+h \nu \rightarrow S^{*}\left|\mathrm{TiO}_{2} \rightarrow \mathrm{S}^{+}\right| \mathrm{TiO}_{2}+\mathrm{e}_{\mathrm{cb}}^{-}\left(\mathrm{TiO}_{2}\right.$ ) (Figure 1A). At a probe wavelength of $840 \mathrm{~nm}$, the decadic molar extinction coefficient of $S^{*}, \mathrm{e}^{-}{ }_{\mathrm{cb}}\left(\mathrm{TiO}_{2}\right)$, and $\mathrm{S}^{+}$species has values of $2.2 \times$ $10^{3}, 1.3 \times 10^{3}$, and $5.4 \times 10^{3} \mathrm{~mol}^{-1} \mathrm{~L} \mathrm{~cm}^{-1}$, respectively. ${ }^{16,21}$ Provided that the charge injection quantum yield is larger than $25 \%$, the extinction coefficient values imply that the transient absorption signal is dominated by the dynamics of the products of the charge injection: $\Delta A\left(\mathrm{~S}^{+}+\mathrm{e}_{\mathrm{cb}}^{-}\right)>\Delta A\left(\mathrm{~S}^{*}\right)$. A spectrokinetic model was established that allowed to isolate and safely extract the kinetics of appearance of $\mathrm{S}^{+}$species formed upon charge injection from signals measured at 840 

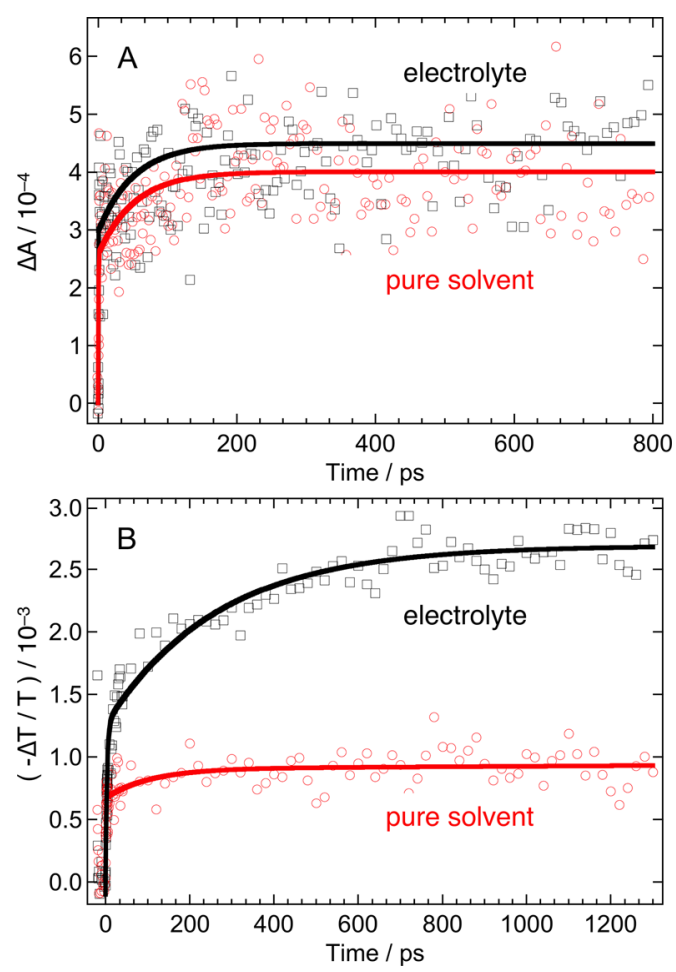

Figure 1. (A) Transient absorbance measured at $\lambda_{\text {probe }}=840 \mathrm{~nm}$ upon fs laser pulse excitation at $\lambda_{\text {pump }}=590 \mathrm{~nm}$ of N719 dye adsorbed on transparent mesoporous $\mathrm{TiO}_{2}$ films. The sensitized films were immersed in pure acetonitrile solvent (red circles) and in a $\left(\mathrm{I}_{3}^{-} / \mathrm{I}^{-}\right)$ redox couple-based liquid electrolyte (black squares). Data were fitted with an analytical convolution function of a Gaussian instrument response and two exponential rises (solid line). (B) Relative amplitude change of the transient $\mathrm{THz}$ signal transmitted through identical samples upon pulsed excitation at $\lambda_{\text {pump }}=590 \mathrm{~nm}$ in similar conditions.

$\mathrm{nm} .{ }^{16,21}$ In accordance with previously reported data, sub-50 fs charge injection is believed to take place from nonthermalized singlet ${ }^{1}$ MLCT excited states of the dye. ${ }^{7,11,12}$

An additional kinetic component with a time constant of 2050 ps was consistently observed, which accounted for $\sim 20 \%$ of the total amplitude of the signal. This significantly slower process was rationalized by charge injection from the relaxed triplet ${ }^{3}$ MLCT excited state of dye molecules, which underwent intersystem crossing in competition with direct injection from the singlet state. ${ }^{7,9,12}$ Figure 1A shows that the efficiency and dynamics of both ultrafast components of the injection process appear to be essentially independent of the medium (pure solvent or electrolyte) surrounding the dye, thus confirming previous measurements carried out in our laboratory with a probe wavelength of $860 \mathrm{~nm} .{ }^{9}$ In the presence of iodide-based electrolytes, incident photon-to-current conversion efficiencies measured with solar cells built from similar systems typically exceed $80 \%$, demonstrating that the electron injection quantum yield must be close to unity. ${ }^{2}$

Charge injection process kinetics was monitored in identical samples by use of time-resolved $\mathrm{THz}$ spectroscopy. ${ }^{22}$ Dyesensitized films were excited by optical ultrashort pulses and probed by single-cycle $\mathrm{THz}$ pulses. The intensity of the $\mathrm{THz}$ transmittance change after optical photoexcitation is proportional to the change of the sample's electric permittivity, which arises from the photogeneration of mobile charge carriers. ${ }^{23}$ As the mobility of $\mathrm{S}^{+}$species in the electrolyte and along the surface is negligible ${ }^{24}$ the relative amplitude change $-\Delta T / T$ of the transmitted $\mathrm{THz}$ radiation is directly related to the effective photoconductivity of the $\mathrm{TiO}_{2}$ film, which is proportional to the product of the density and the mobility of conduction band electrons.

Data reported in Figure 1B show that in pure acetonitrile solvent the time evolution of the $\mathrm{THz}$ signal closely matched the dynamics observed in the NIR: A steep absorbance within the duration of the probe pulse was followed by a second kinetic component developing within the first 200 ps and accounting for $\sim 20 \%$ of the total signal amplitude. When the film was immersed in the electrolyte solution, the initial amplitude change of the $\mathrm{THz}$ signal increased by a factor of 2 . A larger photoconductivity of nanoparticles is indeed expected when the real part of the dielectric function of the surrounding medium increases. ${ }^{25}$ From linear time-domain $\mathrm{THz}$ spectroscopy measurements, the dielectric constants of pure acetonitrile solvent and of the electrolyte were evaluated as being $\varepsilon_{\mathrm{s}}=2.8$ and $\varepsilon_{\mathrm{e}}=3.6$, respectively, at a frequency of $1 \mathrm{THz}$, where the difference $\varepsilon_{\mathrm{s}}-\varepsilon_{\mathrm{e}}$ is maximum. Using the Drude-Smith model for intraparticle conductivity and by applying Maxwell-Garnett effective medium approximation ${ }^{26,27}$ to the $\mathrm{TiO}_{2}$ spherical nanoparticles/liquid composite with a 50:50 volume fraction, an increase by a factor of 2 of the effective photoconductivity of the samples was estimated, in good agreement with the 2 -fold enhancement of the observed initial $\mathrm{THz}$ transmittance change. ${ }^{28}$

Figure 1B shows moreover that a further slow growth of the $\mathrm{THz}$ absorption was recorded with a half-reaction time of $t_{1 / 2} \approx$ 300 ps. This effect of the electrolyte was not observed in the transient absorption of the oxidized state $\left(\mathrm{S}^{+}\right)$of the sensitizer (Figure 1A), where the yield and dynamics of the primary lightinduced electron transfer process appear invariant. Since the concentration of $\mathrm{e}^{-}{ }_{\mathrm{cb}} / \mathrm{S}^{+}$pairs produced upon pulsed excitation is constant, the slow rise of the observed $\mathrm{THz}$ absorption must then reflect an increase of the charge carriers mobility after they have been injected, rather than the density of injected electrons.

Signals with qualitatively analogous dynamics were observed in the mid-IR $\left(\bar{v}=1960 \mathrm{~cm}^{-1}\right)$ upon excitation at $\lambda=540$ $\mathrm{nm} .{ }^{13,14}$ In both reported studies, an ultrafast rise taking place in $<200$ fs was monitored, which was followed by a slow upsurge of the transient absorbance change on the subnanosecond time scale, typically accounting for more than $80 \%$ of the total amplitude. The probed spectral domain was characterized by a broad, featureless absorption spectrum assigned to free conduction band electrons in $\mathrm{TiO}_{2} \cdot{ }^{13}$ When two-dimensional infrared (2D IR) spectroscopy is applied to similar dye-sensitized systems, the broad background absorption of electrons disappears to reveal sharp absorption features belonging to the oxidized state of the dye. ${ }^{29}$ The electron injection kinetics monitored at $\bar{v}=2000 \mathrm{~cm}^{-1}$ in such conditions for a Re sensitizer is strikingly identical to the one we observe at $840 \mathrm{~nm}$ and with $\mathrm{THz}$ probe in the absence of electrolyte (Figure 1A). This suggests that the arrival of mobile carriers in the conduction band might be delayed considerably compared to the femtosecond formation of $\mathrm{S}^{+}$species generated by the injection process and, therefore, that the observation of the appearance of free electrons in titanium dioxide does not necessarily provide direct information on the dynamics of interfacial electron transfer. The delayed emergence of free charge carriers can be rationalized by direct injection of electrons into trap states at the $\mathrm{TiO}_{2} /$ dye interface, which might have their origins in defects or in electrostatic 
interactions as in charge transfer states. The mobility of trapped electrons is indeed close to zero and increases to that of free conduction band carriers in $\mathrm{TiO}_{2}$ nanoparticles upon detrapping.

Figure 2 compares the influence of $\mathrm{Li}^{+}$cations and 4-tertbutylpyridine $(\mathrm{tBP})$, commonly added to $\mathrm{I}_{3}{ }^{-} / \mathrm{I}^{-}$redox couple-
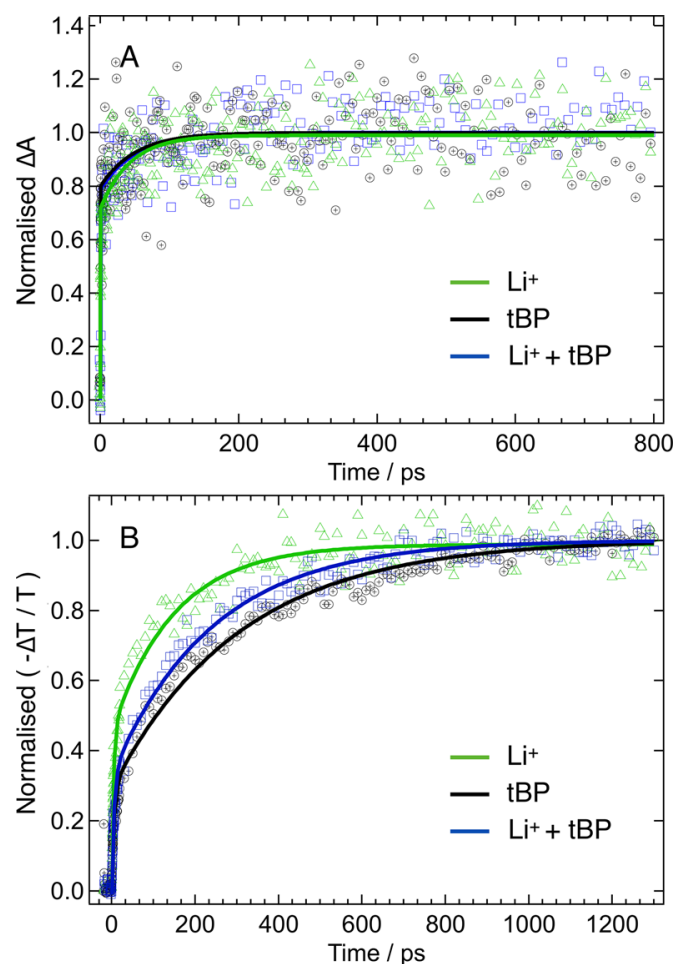

Figure 2. (A) Time course of the transient absorbance measured at $\lambda_{\text {probe }}=840 \mathrm{~nm}$ following fs laser pulse excitation at $\lambda_{\text {pump }}=590 \mathrm{~nm}$ of N719 dye-sensitized mesoporous $\mathrm{TiO}_{2}$ films immersed in solutions of 1,3-dimethylimidazolium iodide (DMII, $\left.0.6 \mathrm{~mol} \mathrm{~L}^{-1}\right)$ and iodine $(0.1$ mol L ${ }^{-1}$ ) in $\mathrm{CH}_{3} \mathrm{CN}$ with lithium iodide (LiI, $0.1 \mathrm{~mol} \mathrm{~L}^{-1}$ ) (green triangles), 4-tert-butylpyridine (tBP, $0.5 \mathrm{~mol} \mathrm{~L}^{-1}$ ) (black circles), or a mixture of both $\mathrm{LiI}\left(0.1 \mathrm{~mol} \mathrm{~L}^{-1}\right)$ and $\mathrm{tBP}\left(0.5 \mathrm{~mol} \mathrm{~L}^{-1}\right)$ (blue squares) added. (B) Relative amplitude change of the transient $\mathrm{THz}$ signal transmitted through identical samples upon pulsed excitation at $\lambda_{\text {pump }}=590 \mathrm{~nm}$ in similar conditions. Traces were normalized at the plateau value extrapolated from the fitting of experimental points at time delays $\geq 1.3 \mathrm{~ns}$.

based electrolytes in DSSCs. Figure 2A shows that the yield and dynamics of the ultrafast electron photoinjection, monitored by the appearance of the $\mathrm{S}^{+}$species characteristic optical absorbance, are not sensitive to the additives. In contrast, the dynamics of $\mathrm{THz}$ transmittance changes (Figure 2B) consist in a fast rise, essentially taking place during the probe pulse, and a second slower component extending on several hundreds of picoseconds. The latter kinetic component is strongly affected by the various additives. The slow component observed in the presence of $\mathrm{tBP}$ represents $70 \%$ of the total transmittance change and is characterized by a half-reaction time $t_{1 / 2}=350$ ps. Addition of $\mathrm{Li}^{+}$cations does not affect significantly the amplitude of the slow component, but it clearly shortens the reaction time.

Similar influence of tBP and $\mathrm{Li}^{+}$species contained in the electrolyte upon $\mathrm{THz}$ signal dynamics was previously reported. ${ }^{27}$ This was assigned to a shift of the flat-band potential of the oxide induced by the adsorption of potential- controlling ions on its surface, which was expected to affect the kinetics of charge injection. The latter interpretation, however, is in contradiction with our observation in the NIR of the appearance of the dye-oxidized state $\mathrm{S}^{+}$, whose rate is unaffected by the electrolyte composition (Figure 2A). Adsorption of $\mathrm{Li}^{+}$cations onto the surface of $\mathrm{TiO}_{2}$ produces a downward shift of the conduction band energy of the semiconductor material. An opposite effect is expected for tBP, whose role in the DSSCs is precisely to neutralize protons released at the surface by the dye upon its adsorption and raise the oxide conduction band edge energy. ${ }^{30}$ Though both additives mixed with a large concentration of iodide in the electrolyte yielded a similar effect on the $\mathrm{THz}$ signal compared to the pure solvent, which was to add a slow component in the hundreds of picoseconds time domain and to markedly increase the transient conductivity.

In a quest of a new rationale for the observed effect of the electrolyte, we performed time-resolved $\mathrm{THz}$ photoconductivity measurements in the conditions of Figure $1 \mathrm{~B}$ with various pump wavelengths ranging from $590 \mathrm{~nm}$ down to $420 \mathrm{~nm}$. Figure 3 displays the obtained results restricted to a selection of

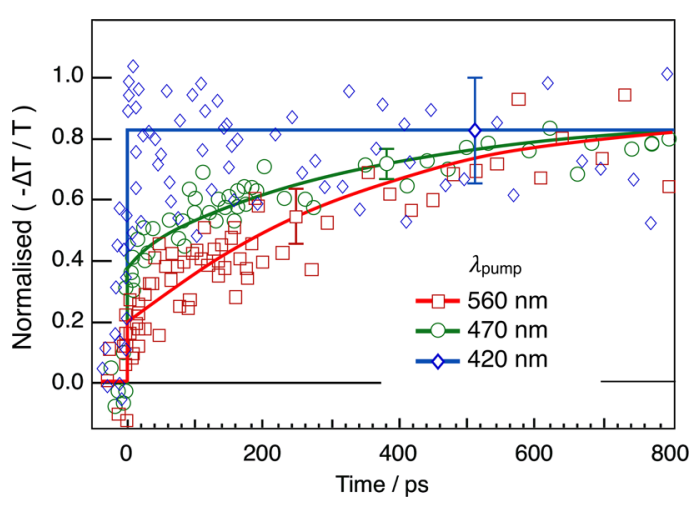

Figure 3. Relative amplitude change of the transient $\mathrm{THz}$ signal transmitted through N719 dye-sensitized $\mathrm{TiO}_{2}$ samples in a $\left(\mathrm{I}_{3}^{-} / \mathrm{I}^{-}\right)$ redox couple-based liquid electrolyte upon pulsed excitation at $\lambda_{\text {pump }}=$ $560 \mathrm{~nm}$ (squares), $470 \mathrm{~nm}$ (circles), and $420 \mathrm{~nm}$ (diamonds). Traces were normalized to the plateau value extrapolated from fitting curves at a delay time of 800 ps.

three different pump wavelengths. For $\lambda_{\text {pump }}=560 \mathrm{~nm}$, a fast initial part amounting to ca. $25 \%$ of the total signal was followed by a slower rise of the photoconductivity, whose time constant was $t_{1 / 2}=350 \mathrm{ps}$. At shorter pump wavelengths, the fast initial part was observed to increase, reaching $50 \%$ of the total signal at $470 \mathrm{~nm}$ and practically $100 \%$ for $\lambda_{\text {pump }} \leq 450 \mathrm{~nm}$. At large excitation wavelengths, a majority of injected electrons seem to be primarily localized and acquire their mobility only within hundreds of picoseconds in the presence of an electrolyte. Conversely, larger excess excitation energies appear to produce an increasing initial proportion of mobile carriers, eventually reaching a situation where no slow rise of the mobility in the subnanosecond time scale takes place anymore. Blank experiments carried out with bare $\mathrm{TiO}_{2}$ films pumped at $\lambda \geq 420 \mathrm{~nm}$ in identical conditions yielded no $\mathrm{THz}$ absorption signal.

In functional DSSCs containing $\mathrm{I}_{3}^{-} / \mathrm{I}^{-}$redox couple-based liquid electrolytes, holes are transferred to iodide anions in the microsecond time scale and do not interfere then with subnanosecond carriers dynamics. This picture is complicated in solid-state dye-sensitized solar cells (ss-DSSCs), where the 
liquid electrolyte is replaced by spiro-MeOTAD, an amorphous solid organic hole transport material (HTM) filling the pores of the dye-sensitized nanostructured $\mathrm{TiO}_{2}$ film. ${ }^{31}$ At the hybrid organic-inorganic heterojunction, hole injection from the dye oxidized state into the $\mathrm{HTM}, \mathrm{S}^{+} \mid \mathrm{TiO}_{2}+\mathrm{HTM} \rightarrow \mathrm{SlTiO}_{2}+$ $\mathrm{h}^{+}(\mathrm{HTM})$, takes place in the picoseconds time scale, typically 4-5 orders of magnitude faster than in liquid electrolytes. ${ }^{32}$ Solid-state samples were prepared by adsorbing the dye cisbis(isothiocyanato $)\left(2,2^{\prime}\right.$-bipyridyl-4,4' -dicarboxylate $)\left(4,4^{\prime}\right.$-dinonyl-2'-bipyridyl) $\mathrm{Ru}^{\text {II }}$ (Z907) on mesoporous $\mathrm{TiO}_{2}$ films. ${ }^{33}$ Z907 is spectroscopically and thermodynamically similar to the N719 carboxylated derivative used in liquid electrolyte-based systems. The hydrophobic dinonyl aliphatic moiety of Z907 allows for a better wetting of the dye-sensitized surface by the organic HTM and the formation of a more conformal heterojunction. ${ }^{34}$ Hence, its use is preferred to that of N719 dye in the fabrication of efficient solid-state DSSCs. Upon pulsed laser excitation, solid-state samples displayed a steep rise of transient absorption observed at short times, corresponding to the appearance of the oxidized state of the dye produced by ultrafast electron injection (Figure 4A). In the subnanosecond time domain, a decay of the signal was observed in the presence of HTM, which is assigned to the regeneration of the dye ground state by injection of a hole into the organic material. At the probe wavelength of $840 \mathrm{~nm}$, the dye excited state $S^{*}$, the
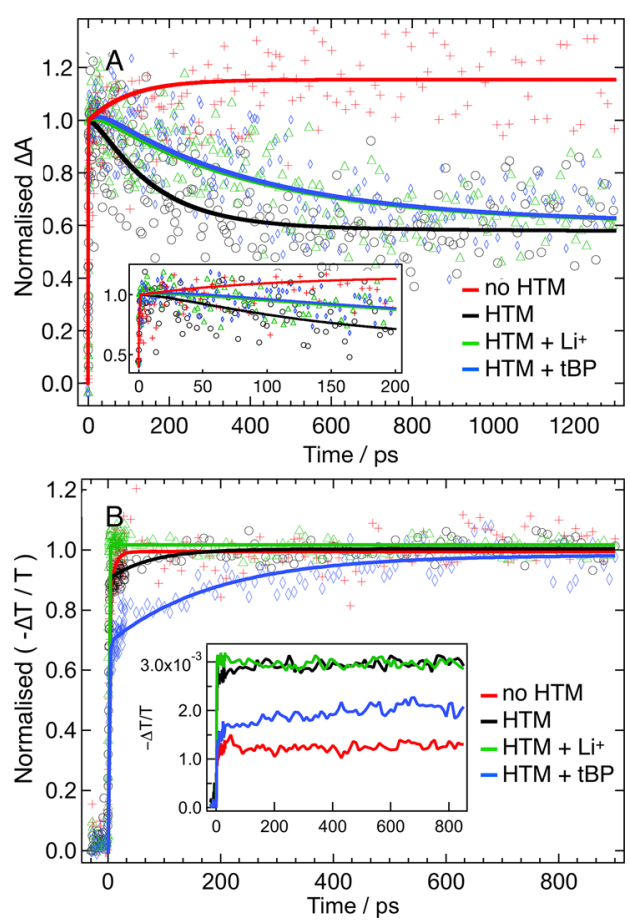

Figure 4. (A) Hole injection dynamics probed at $\lambda_{\text {probe }}=840 \mathrm{~nm}$ of solid-state samples following femtosecond laser pulse excitation at $\lambda_{\text {pump }}=590 \mathrm{~nm}$ of the amphiphilic ruthenium complex sensitizer cis$\mathrm{RuLL}^{\prime}(\mathrm{SCN})_{2}\left(\mathrm{~L}=4,4^{\prime}\right.$-dicarboxylic acid-2,2'-bipyridine, $\mathrm{L}^{\prime}=4,4^{\prime}$ dinonyl-2,2'-bipyridine) (Z907). The pores of the dye-sensitized nanocrystalline $\mathrm{TiO}_{2}$ films were left empty (red crosses), filled by spincoating with pristine spiro-MeOTAD (black circles) or filled with the HTM doped with lithium bis(trifluoromethanesulfonyl)imide (LiTFSI, $15 \mathrm{~mol} \%$ ) (green triangles) or tBP (81 mol \%) (blue diamonds). (B) Normalized transient $\mathrm{THz}$ transmittance changes of the same samples upon pulsed excitation at $\lambda_{\text {pump }}=590 \mathrm{~nm}$ in similar conditions. The inset shows the relative amplitude changes for the investigated systems before normalization. oxidized state $\mathrm{S}^{+}$, conduction band electrons $\mathrm{e}_{\mathrm{cb}}^{-}$, and the oxidized state of the hole transport medium $\mathrm{h}^{+}(\mathrm{HTM})$ all contribute to the transient absorbance signal. Here again, the respective contributions were unravelled using a model including the kinetic heterogeneity of electron injection. ${ }^{16,21}$ Fitting of experimental data then yielded a fast regeneration time constant $\tau=153 \mathrm{ps}\left(t_{1 / 2} \approx 100 \mathrm{ps}\right)$ for pristine spiroMeOTAD, $\tau=370$ ps for $\mathrm{Li}^{+}$-doped HTM, and $\tau=384$ ps $\left(t_{1 / 2}\right.$ $\approx 270 \mathrm{ps}$ ) for $\mathrm{tBP}$-containing samples.

Similar to the effect of the electrolyte, filling the pores of the nanostructured $\mathrm{TiO}_{2}$ film with the organic hole-conducting material produced a marked increase by a factor 2.3 of the transient $\mathrm{THz}$ conductivity signal measured at the end of the probe pulse (Figure 4B). An additional slow component accounting for approximately $10 \%$ of the signal was also observed with a half reaction time $t_{1 / 2} \approx 100 \mathrm{ps}$, concomitant with the hole injection into the HTM. Blank experiments demonstrated that the transient photoconductivity signal is not due to holes in the HTM, whose mobility by hopping mechanism is practically null at $\mathrm{THz}$ frequency, but only to conduction band electrons in $\mathrm{TiO}_{2}$. Figure 4A shows that $\mathrm{Li}^{+}$ and $\mathrm{tBP}$ species inserted in the organic hole transport material yielded identical hole injection rates. The same two additives, however, had a profoundly different effect upon the $\mathrm{THz}$ signal dynamics (Figure 4B). In the presence of $\mathrm{Li}^{+}$cations, the photoconductance reached immediately its maximum value, and no slow component was observed. On the contrary, addition of tBP to the spiro-MeOTAD limited the initial $\mathrm{THz}$ photoconductivity to a level comparable to the system deprived of HTM. A slow rise component was observed in this case, which corresponded to an increase by $50 \%$ of the average mobility of photoinjected electrons with a time constant $t_{1 / 2} \approx$ 200 ps.

\section{DISCUSSION}

Ultrafast optical pump-probe transient absorption measurements monitoring the dye sensitizer's oxidized state yield an evaluation of the population of electrons photoinjected in $\mathrm{TiO}_{2}$ upon laser pulsed excitation. Besides, time-resolved $\mathrm{THz}$ spectroscopy experiments provide a direct estimate of the photoconductivity of the nanocrystalline oxide material, which stands for the product of the injected conduction band electrons' density and average mobility. Combining both techniques by applying them on the same samples allows then extracting the time evolution of the carrier's mobility. In liquid junction systems, a marked increase of the carrier mobility by a factor of $\sim 2$ is observed upon addition of electrolyte species in the solvent. This indicates that about half of the photoinjected electrons get trapped within the first picosecond following ultrafast interfacial electron transfer from the dye's excited state into the conduction band of $\mathrm{TiO}_{2}$. The upsurge of the mobility of conduction band electrons in the subnanosecond time scale, long after they have been injected into the oxide semiconductor, the ability of an electrolyte and in particular that of small cations such as $\mathrm{Li}^{+}$to detrap electrons, and the effect of the excitation wavelength point toward the formation and dissociation of charge transfer states (CTSs) at the interface. According to this interpretation, Coulomb interaction between injected electrons trapped at the surface of the solid and positive charges represented by adsorbed oxidized dye species $\mathrm{S}^{+}$prevent part of the injected charge carriers from moving during the first picoseconds and from contributing to the $\mathrm{THz}$ photoconductivity. In the 
presence of a concentrated electrolyte, bound electron-hole pairs $\left(\mathrm{e}^{-}{ }_{\mathrm{cb}} \cdots \mathrm{S}^{+}\right)$formed across the interface dissociate upon polarization reorganization of the ionic environment in the subnanosecond time scale, screening the Coulomb interaction and diminishing the CTSs binding energy. Freed conduction band electrons can then contribute to the photoconductivity of $\mathrm{TiO}_{2}$ nanoparticles, whose $\mathrm{THz}$ absorption increases markedly. Although acetonitrile is a polar solvent, it is apparently unable to dissociate charge transfer states, which appear in contact with the pure solvent to be remarkably stable for more than a nanosecond. A large excess excitation energy provided by optical pumping at short wavelength appears to prevent the formation of CTSs or speed up considerably their dissociation, presumably because it exceeds the binding energy of the electron-hole pair in the charge transfer state.

This rationale based on the formation and dissociation of charge transfer states is able to explain the effect of $\mathrm{Li}^{+}$and $\mathrm{tBP}$ additives in the liquid electrolyte as well as in the solid organic hole transport material. In liquid junction systems, CTSs formed upon ultrafast photoinduced charge injection dissociate in the subnanosecond time scale only in the presence of an electrolyte. This dissociation is faster for small $\mathrm{Li}^{+}$cations able to quickly rearrange on the surface and effectively screen trapped electrons. The charge-screening kinetics, whose estimated rate constant is here $k=3 \times 10^{9} \mathrm{~s}^{-1}$, appears to be $10^{5}$ times faster compared to the value obtained from spectroelectrochemical and Stark spectroscopy measurements applied to a comparable system. ${ }^{35}$ This shows that local reorganization of ions adsorbed to the surface, which allow for the liberation of electrons trapped in CTSs is much faster that the macroscopic reorganization of the electrolyte and solvent molecules around dye-sensitized $\mathrm{TiO}_{2}$ nanoparticles. Addition of tBP does not provide supplementary ions in the electrolyte. Conversely, this additives' role is to capture protons that could be present at the surface. ${ }^{30}$ As protons are expected to have the same effect as lithium cations and promote the dissociation of CTSs, the effect of $\mathrm{tBP}$ opposes to that of $\mathrm{Li}^{+}$by slowing down the charge separation at the interface.

In solid-state samples containing pristine spiro-MeOTAD hole transport material, $\mathrm{H}^{+}$cations freed during the adsorption of the protonated $\mathrm{Z} 907$ dye sensitizer are the only ionic species that could be present at the surface of $\mathrm{TiO}_{2}$. Contrary to N719 dye, the anchoring carboxylic groups of Z907 complex prior to adsorption are protonated. A larger concentration of $\mathrm{H}^{+}$ associated with the surface is therefore expected in ss-DSSCs compared to the liquid electrolyte-based systems. In the presence of HTM, localization of photoinjected electrons is practically hindered with a large initial photoconductivity signal and only a small fraction of trapped electrons being released in the picosecond time scale. The latter slow contribution is totally suppressed upon addition of $\mathrm{Li}^{+}$cations. $\mathrm{tBP}$-doping of spiro-MeOTAD reduces ions presence at the interface by neutralizing adsorbed protons. As a consequence, about half of the photogenerated electrons are initially trapped at the interface and freed later, concomitantly with hole injection into the HTM, with a time constant $t_{1 / 2}=180$ ps. This suggests that hole injection dynamics is the cause of the observed slow increase in the $\mathrm{THz}$ mobility of injected electrons rather than its consequence.

Charge transfer states and charge transfer excitons are wellestablished concepts in organic photovoltaics. A lot of efforts are currently devoted to fully understand the formation and dissociation of CTSs. ${ }^{9,36-40}$ At organic heterojunctions, the low dielectric constant of materials favors the formation of CTSs, and electron-hole binding energies of the order of $250 \mathrm{meV}$ $(\sim 10 k T)$ are typical. ${ }^{41}$ At hybrid interfaces, involving a low dielectric constant inorganic metal oxide such as $\mathrm{ZnO}\left(\varepsilon_{\mathrm{rGHz}}=\right.$ $3.7),{ }^{42}$ evidence has been found that electron injection proceeds over an intermediate, electrostatically bound state. $^{43-45}$ Our present work provides evidence that CTSs can as well exist in DSSCs at the surface of $\mathrm{TiO}_{2}$, a material characterized by a strong relative permittivity $\left(\varepsilon_{\mathrm{rGHz}}=17\right) .{ }^{46}$ This finding is consistent with a previously suggested recombination mechanism occurring via surface Coulomb traps. ${ }^{47,48}$ It shows that the bulk dielectric function of the solid is not appropriate to predict the screening of electrostatic interactions between electrons trapped in surface states and holes localized on neighboring oxidized adsorbed dye molecules.

A new picture of a charge injection mechanism involving the formation and dissociation of charge transfer states is sketched in Figure 5. Following absorption of light, vibrationally

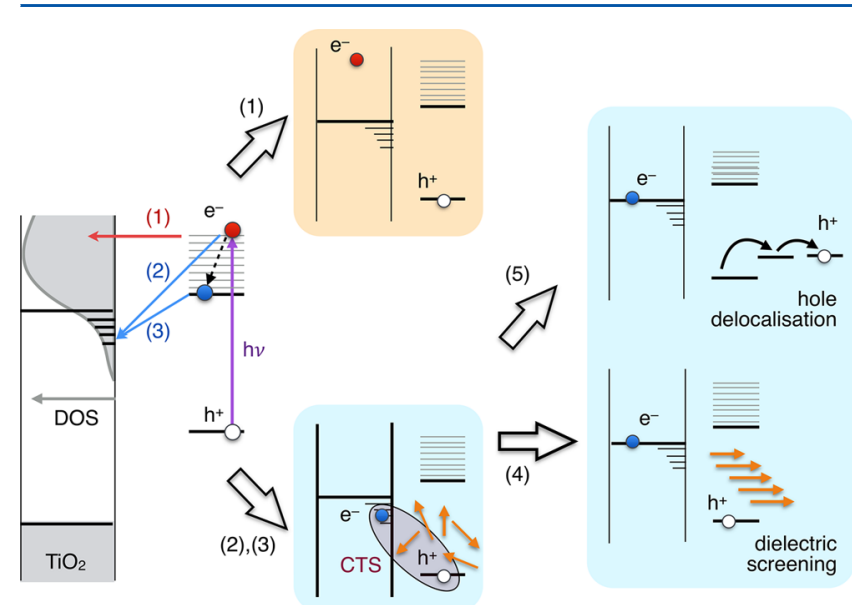

Figure 5. Scheme of energy levels and processes involved in charge transfer states formation and dissociation in DSSCs. An explanation is provided in the text.

unrelaxed excited dye sensitizer molecules optimally coupled to the $\mathrm{TiO}_{2}$ surface undergo electron injection in the conduction band of the solid. This process takes place on $a$ $<50 \mathrm{fs}$ time scale and competes kinetically with vibrational relaxation. ${ }^{11,12}$ Injection from hot molecular excited states can proceed isoenergetically, yielding hot electrons in the conduction band, whose kinetic energy carry away the excess optical excitation energy (Figure 5, process 1). Alternatively, electrons can be injected directly at the bottom of the conduction band or into underlying trap states (Figure 5, process 2 ). In the first case, a hot electron would thermalize to the conduction band bottom edge within a few hundreds of femtoseconds, but the probability of being trapped into a surface state at the immediate proximity of the oxidized dye molecule is obviously low. In the second case, the excess excitation energy is converted into vibrational excitation of the dye cation, and hence, the localized injected electron might be trapped in an interfacial charge transfer state. The same result would be obtained if electron injection occurs from vibrationally relaxed singlet ${ }^{1} \mathrm{MLCT}$ state of the sensitizer or from a triplet ${ }^{3}$ MLCT state yielded by ultrafast intersystem crossing (Figure 5, process 3). ${ }^{49,50}$ Since the excess excitation energy in this case is reduced, the formation of a CTSs between 
correlated electrons and dye cations should be more probable. The binding energy of excitons is expected to be sensitive to changes in the surrounding charge distribution. Here we propose that CTSs are split by a local redistribution of ionic charges and dipoles (Figure 5, process 4 ) present at the surface or by fast hole injection of the dye cation into an HTM (Figure 5, process 5).

The geometry of the dye-sensitizer molecule adsorbed on the surface is expected to influence the distance at which injected electrons and holes localized in the oxidized dye molecule interact and, hence, modulate the strength of the Coulomb attraction between them. For N719 dye anchored on $\mathrm{TiO}_{2}$ anatase (101) facet, the $\mathrm{e}^{-}-\mathrm{h}^{+}$minimum separation distance is ca. $7 \AA$ (Figure 6). Assuming an average dielectric constant of the intra-CTS medium $\varepsilon_{\mathrm{r}}=3$, an upper limit for the binding energy $E_{\mathrm{b}}=0.7 \mathrm{eV}$ is estimated from the Coulomb law.

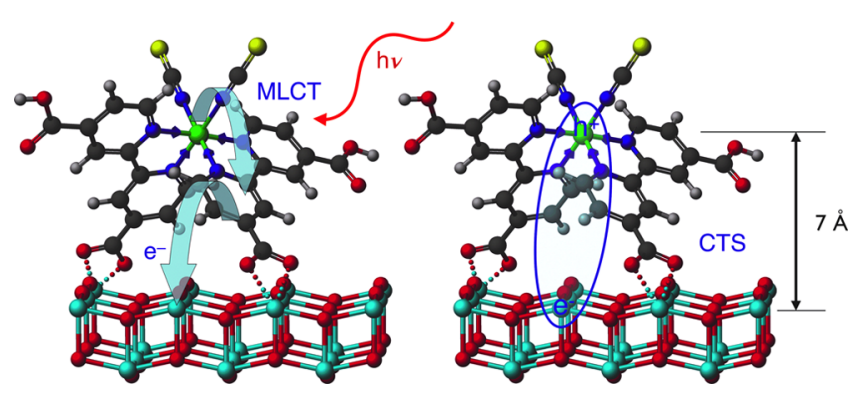

Figure 6. Ball-and-stick molecular model of N719 dye-sensitizer adsorbed on $\mathrm{TiO}_{2}$ anatase (101) surface. Ultrafast electron injection into the solid oxide takes place upon photoexcitation of the $\mathrm{Ru}$ (II) complex by a metal-to-ligand charge transfer (MLCT) transition. Provided the excess excitation energy is not too large $\left(\Delta E_{\mathrm{ex}}<1 \mathrm{eV}\right.$, $\lambda_{\text {pump }} \geq 470 \mathrm{~nm}$ ), a charge transfer state (CTS) is formed through Coulombic interaction between the positive charge $\left(\mathrm{h}^{+}\right)$located within the HOMO of the oxidized dye cation and the injected electron $\left(\mathrm{e}^{-}\right)$ trapped at a neighboring, uncoordinated surface $\mathrm{Ti}(\mathrm{IV})$ site, with an $\mathrm{e}^{-}-\mathrm{h}^{+}$separation distance $\geq 7 \AA$.

Hot CTS are produced naturally by encompassing the excess excitation energy $\Delta E_{\text {ex }}$ of the dye defined as $\Delta E_{\text {ex }}=h \nu-\Delta E_{0,0}$ $-\Delta G_{\text {inj, }}^{0}$ where $h \nu$ is the absorbed photon energy, $\Delta E_{0,0}$ the excitation energy of the dye at its absorption threshold, and $\Delta G^{0}{ }_{\text {inj }}$ the standard free energy for charge injection from the lowest excited state of the sensitizer to the bottom edge of the conduction band of the acceptor material. The absorption threshold of adsorbed N719 dye is at a wavelength of $750 \mathrm{~nm}$ corresponding to $\Delta E_{0,0}=1.65 \mathrm{eV}$. For N719 photoexcited at $\lambda_{\mathrm{ex}}$ $=470 \mathrm{~nm}$, in conditions where approximately half of the photoinjected electrons appear to be trapped in CTS (Figure 3), and assuming $\Delta G^{0}{ }_{\text {inj }}=0.1 \mathrm{eV}$, a value $\Delta E_{\mathrm{ex}}=\sim 1.1 \mathrm{eV}$ is calculated. This excess excitation energy largely exceeds the Coulombic binding energy of charge transfer states. However, it closely matches the CTS dissociation energy $E_{\mathrm{d}}$ calculated as the sum $E_{\mathrm{d}}=E_{\mathrm{b}}+E_{\mathrm{t}}=\sim 1.1 \mathrm{eV}$, where $E_{\mathrm{t}}=\sim 0.4 \mathrm{eV}$ is the energy depth of electron trap states at the surface of $\mathrm{TiO}_{2}$ nanoparticles. ${ }^{51}$

\section{CONCLUSION}

Ultrafast optical transient absorption and time-resolved terahertz spectroscopies were applied to the photoanode of dye-sensitized solar cells based on $\mathrm{Ru}$ (II) complexes adsorbed on mesoporous titania films. The combination of both techniques allowed monitoring the time evolution of the mobility of photoinjected electrons in $\mathrm{TiO}_{2}$. Provided the excess excitation energy of the dye sensitizer was not too large $\left(\lambda_{\text {exc }} \geq 450 \mathrm{~nm}\right)$, a significant part of the injected carriers was found to be trapped within a subpicoseconds time scale. Detrapping of electrons with a time constant of several hundreds of picoseconds was observed to take place in the presence of ionic species or upon positive charge transfer to a solid-state hole transport material. These observations are rationalized by the formation and dissociation of charge transfer states, which are arising from the Coulomb interaction between electrons trapped at the surface of titania and positive charges located on oxidized dye cations. Irradiation of sensitizer molecules in the blue part of their absorption spectrum $\left(\lambda_{\text {exc }}\right.$ $<450 \mathrm{~nm}$ ) results in a large excitation excess energy, which prevents the trapping of photoinjected electrons or causes the prompt dissociation of charge transfer states on the subpicoseconds time scale.

Results obtained here and conclusions drawn from them reconcile what appeared so far as contradictory reports regarding charge injection kinetics in dye-sensitized $\mathrm{TiO}_{2}$ and provide a new, consistent interpretation of previous observations. They highlight the importance of dielectric screening by ions in carrier separation, which is of particular importance in solid-state dye-sensitized solar cells, where the hole transport medium does not intrinsically contain charges. They shed new insight into the possible mechanism of action of dopants, such as in particular $\mathrm{Li}^{+}$and $\mathrm{H}^{+}$cations. They show that the existence of charge transfer states is a common property of liquid electrolyte-based and solid-state dye-sensitized solar cells. Finally, they suggest a unified picture for free carriers generation and separation in OPV and hybrid organicinorganic photovoltaic systems using wide-bandgap semiconductors, where the involvement of interfacial charge transfer excitons and charge transfer states represents a paradigm shift.

\section{ASSOCIATED CONTENT}

\section{S Supporting Information}

The Supporting Information is available free of charge on the ACS Publications website at DOI: 10.1021/acs.jpcc.5b06911.

Details on femtosecond transient absorption data treatment, confidence intervals of the fitting of transient absorbance experimental points, and blank measurements to assess the contribution to the $\mathrm{THz}$ absorption signal of holes in spiro-MeOTAD HTM (PDF)

\section{AUTHOR INFORMATION}

\section{Corresponding Author}

*E-mail je.moser@epfl.ch; phone +41 216933628 (J.-E.M.).

\section{Present Addresses}

J.C.B.: Department of Chemistry, Université de Fribourg, CH1700 Fribourg, Switzerland.

A.M.: Department of Chemistry, University of Washington, Seattle, WA 98195-1700.

\section{Notes}

The authors declare no competing financial interest.

\section{ACKNOWLEDGMENTS}

Funding of this work has been provided by the Swiss National Science Foundation (grant no. 200021_157215) and the National Center of Competence in Research program "Molecular Ultrafast Science and Technology" (NCCRMUST), a research instrument of the SNSF. The authors 
thank Amalie Dualeh for help in the preparation of the solidstate samples, Joël Teuscher for fruitful discussions, and Pascal Comte and Shaik M. Zakeeruddin for providing $\mathrm{TiO}_{2}$ pastes, dyes, and electrolytes used in this study.

\section{REFERENCES}

(1) Grätzel, M. Photoelectrochemical Cells. Nature 2001, 414, 338344.

(2) Hagfeldt, A.; Boschloo, G.; Sun, L.; Kloo, L.; Pettersson, H. DyeSensitized Solar Cells. Chem. Rev. 2010, 110, 6595-6663.

(3) Dye-Sensitized Solar Cells; Kalyanasundaram, K., Ed.; EPFL Press: Lausanne, Switzerland, 2010.

(4) Hardin, B. E.; Snaith, H. J.; McGehee, M. D. The Renaissance of Dye-Sensitized Solar Cells. Nat. Photonics 2012, 6, 162-169.

(5) Ardo, S.; Meyer, G. J. Photodriven Heterogeneous Charge Transfer with Transition-Metal Compounds Anchored to $\mathrm{TiO}_{2}$ Semiconductor Surfaces. Chem. Soc. Rev. 2009, 38, 115-164.

(6) Moser, J.-E. Dynamics of Interfacial and Surface Electron Transfer Processes. In Dye-Sensitized Solar Cells; Kalyanasundaram, K., Ed.; EPFL Press: Lausanne, Switzerland, 2010; pp 403-456.

(7) Asbury, J. B.; Anderson, N. A.; Hao, E.; Ai, X.; Lian, T. Parameters Affecting Electron Injection Dynamics from Ruthenium Dyes to Titanium Dioxide Nanocrystalline Thin Film. J. Phys. Chem. B 2003, 107, 7376-7386.

(8) Wenger, B.; Grätzel, M.; Moser, J.-E. Rationale for Kinetic Heterogeneity of Ultrafast Light-Induced Electron Transfer from $\mathrm{Ru}$ (II) Complex Sensitizers to Nanocrystalline $\mathrm{TiO}_{2}$. J. Am. Chem. Soc. 2005, 127, 12150-12151.

(9) Teuscher, J.; Décoppet, J.-D.; Punzi, A.; Zakeeruddin, S. M.; Moser, J.-E.; Grätzel, M. Photoinduced Interfacial Electron Injection Dynamics in Dye-Sensitized Solar Cells under Photovoltaic Operating Conditions. J. Phys. Chem. Lett. 2012, 3, 3786-3790.

(10) Kallioinen, J.; Benkö, G.; Myllyperkiö, P.; Khriachtchev, L.; Skårman, B.; Wallenberg, R.; Tuomikoski, M.; Korppi-Tommola, J.; Sundström, V.; Yartsev, A. P. Photoinduced Ultrafast Dynamics of $\mathrm{Ru}(\text { dcbpy })_{2}(\mathrm{NCS})_{2}$-Sensitized Nanocrystalline $\mathrm{TiO}_{2}$ Films: The Influence of Sample Preparation and Experimental Conditions. J. Phys. Chem. B 2004, 108, 6365-6373.

(11) Bräm, O.; Cannizzo, A.; Chergui, M. Ultrafast Fluorescence Studies of Dye Sensitized Solar Cells. Phys. Chem. Chem. Phys. 2012, 14, 7934-7937.

(12) Borgwardt, M.; Wilke, M.; Kampen, T.; Mähl, S.; Xiang, W.; Spiccia, L.; Lange, K. M.; Kiyan, J. Y.; Aziz, E. F. Injection Kinetics and Electronic Structure at the $\mathrm{N} 719 / \mathrm{TiO}_{2}$ Interface Studied by Means of Ultrafast XUV Photoemission Spectroscopy. J. Phys. Chem. C 2015, 119, 9099-9107.

(13) Juozapavicius, M.; Kaucikas, M.; van Thor, J. J.; O’Regan, B. C. Observation of Multiexponential Pico- to Subnanosecond Electron Injection in Optimized Dye-Sensitized Solar Cells with Visible-Pump Mid-Infrared-Probe Transient Absorption Spectroscopy. J. Phys. Chem. C 2013, 117, 116-123. A mid-IR transient absorption spectrum is provided in the Supporting Information file (http://pubs.acs.org/doi/ suppl/10.1021/jp309732z).

(14) Antila, L. J.; Myllyperkiö, P.; Mustalahti, S.; Lehtivuori, H.; Korppi-Tommola, J. Injection and Ultrafast Regeneration in DyeSensitized Solar Cells. J. Phys. Chem. C 2014, 118, 7772-7780.

(15) Brauer, J. C. Linear and Time-Resolved THz Spectroscopy of Photonic and Charge-Transporting Systems. PhD Thesis No. 5444, Ecole Polytechnique Fédérale de Lausanne, Lausanne, Switzerland, 2012.

(16) Marchioro, A.; Dualeh, A.; Punzi, A.; Grätzel, M.; Moser, J.-E. Effect of Posttreatment of Titania Mesoscopic Films by $\mathrm{TiCl}_{4}$ in SolidState Dye-Sensitized Solar Cells: A Time-Resolved Spectroscopy Study. J. Phys. Chem. C 2012, 116, 26721-26727. A detailed model for the treatment of transient absorption data collected at a probe wavelength of $840 \mathrm{~nm}$ is provided in the Supporting Information file (http://pubs.acs.org/doi/suppl/10.1021/jp309799u).
(17) Ito, S.; Chen, P.; Comte, P.; Nazeeruddin, M. K.; Liska, P.; Péchy, P.; Grätzel, M. Fabrication of Screen-Printing Pastes From $\mathrm{TiO}_{2}$ Powders for Dye-Sensitised Solar Cells. Prog. Photovoltaics 2007, $15,603-612$.

(18) Nazeeruddin, M. K.; Zakeeruddin, S. M.; Humphry-Baker, R.; Jirousek, M.; Liska, P.; Vlachopoulos, N.; Shklover, V.; Fischer, C.-H.; Grätzel, M. Acid-Base Equilibria of (2,2'-Bipyridyl-4,4'-dicarboxylic acid)ruthenium(II) Complexes and the Effect of Protonation on Charge-Transfer Sensitization of Nanocrystalline Titania. Inorg. Chem. 1999, 38, 6298-6305.

(19) Ding, I.-K.; Tétreault, N.; Brillet, J.; Hardin, B. E.; Smith, E. H.; Rosenthal, S. J.; Sauvage, F.; Grätzel, M.; McGehee, M. D. Pore-Filling of spiro-OMeTAD in Solid-State Dye-Sensitized Solar Cells: Quantification, Mechanism, and Consequences for Device Performance. Adv. Funct. Mater. 2009, 19, 2431-2436.

(20) Gao, F.; Wang, Y.; Shi, D.; Zhang, J.; Wang, M.; Jing, X.; Humphry-Baker, R.; Wang, P.; Zakeeruddin, S. M.; Grätzel, M. Enhance the Optical Absorptivity of Nanocrystalline $\mathrm{TiO}_{2}$ Film with High Molar Extinction Coefficient Ruthenium Sensitizers for High Performance Dye-Sensitized Solar Cells. J. Am. Chem. Soc. 2008, 130, 10720-10728.

(21) Marchioro, A. Interfacial Charge Transfer Dynamics in SolidState Hybrid Organic-Inorganic Solar Cells. PhD Thesis No. 6221, Ecole Polytechnique Fédérale de Lausanne, Lausanne, Switzerland, 2014; pp 95-100.

(22) Schmuttenmaer, C. A. Exploring Dynamics in the Far-Infrared with Terahertz Spectroscopy. Chem. Rev. 2004, 104, 1759-1780.

(23) Kaindl, R. A.; Averitt, R. D. In THz Spectroscopy: Principles and Applications; Dexheimer, S. L., Ed.; CRC Press: Boca Raton, FL, 2008.

(24) Wang, Q.; Zakeeruddin, S. M.; Nazeeruddin, M. K.; HumphryBaker, R.; Grätzel, M. Molecular Wiring of Nanocrystals: NCSEnhanced Cross-Surface Charge Transfer in Self-Assembled RuComplex Monolayer on Mesoscopic Oxide Films. J. Am. Chem. Soc. 2006, 128, 4446-4452.

(25) Hendry, E.; Koeberg, M.; O’Regan, B.; Bonn, M. Local Field Effects on Electron Transport in Nanostructured $\mathrm{TiO}_{2}$ Revealed by Terahertz Spectroscopy. Nano Lett. 2006, 6, 755-759.

(26) Choy, T. C. Effective Medium Theory; Clarendon Press: Oxford, UK, 1999.

(27) Němec, H.; Kužel, P.; Sundström, V. Charge Transport in Nanostructured Materials for Solar Energy Conversion Studied by Time-Resolved Terahertz Spectroscopy. J. Photochem. Photobiol., A 2010, 215, 123-139.

(28) Pijpers, J. J. H.; Ulbricht, R.; Derossi, S.; Reek, J. N. H.; Bonn, M. Picosecond Electron Injection Dynamics in Dye-Sensitized Oxides in the Presence of Electrolyte. J. Phys. Chem. C 2011, 115, 2578-2584.

(29) Xiong, W.; Laaser, J. E.; Paoprasert, P.; Franking, R. A.; Hamers, R. J.; Gopalan, P.; Zanni, M. T. Transient 2D IR Spectroscopy of Charge Injection in Dye-Sensitized Nanocrystalline Thin Films. J. Am. Chem. Soc. 2009, 131, 18040-18041.

(30) Boschloo, G.; Häggman, L.; Hagfeldt, A. Quantification of the Effect of 4-tert-Butylpyridine Addition to $\mathrm{I}^{-} / \mathrm{I}_{3}{ }^{-}$Redox Electrolytes in Dye-Sensitized Nanostructured $\mathrm{TiO}_{2}$ Solar Cells. J. Phys. Chem. B 2006, 110, 13144-13150.

(31) Bach, U.; Lupo, D.; Comte, P.; Moser, J. E.; Weissörtel, F.; Salbeck, J.; Spreitzer, H.; Grätzel, M. Solid-State Dye-Sensitized Mesoporous $\mathrm{TiO}_{2}$ Solar Cells with High Photon-to-Electron Conversion Efficiencies. Nature 1998, 395, 583-585.

(32) Bach, U.; Tachibana, Y.; Moser, J.-E.; Haque, S. A.; Durrant, J. R;; Grätzel, M.; Klug, D. R. Charge Separation in Solid-State DyeSensitized Heterojunction Solar Cells. J. Am. Chem. Soc. 1999, 121, $7445-7446$.

(33) Wang, P.; Zakeeruddin, S. M.; Moser, J.-E.; Nazeeruddin, M. K.; Sekiguchi, T.; Grätzel, M. A Stable Quasi-Solid-State Dye-Sensitized Solar Cell with an Amphiphilic Ruthenium Sensitizer and Polymer Gel Electrolyte. Nat. Mater. 2003, 2, 402-407.

(34) Melas-Kyriazi, J.; Ding, I. K.; Marchioro, A.; Punzi, A.; Hardin, B. E.; Burkhard, G. F.; Tétreault, N.; Grätzel, M.; Moser, J.-E.; McGehee, M. D. The Effect of Hole Transport Material Pore Filling 
on Photovoltaic Performance in Solid-State Dye-Sensitized Solar Cells. Adv. Energy Mater. 2011, 1, 407-414.

(35) O’Donnell, R. M.; Ardo, S.; Meyer, G. J. Charge-Screening Kinetics at Sensitized $\mathrm{TiO}_{2}$ Interfaces. J. Phys. Chem. Lett. 2013, 4, 2817-2821.

(36) Brédas, J.-L.; Norton, J. E.; Cornil, J.; Coropceanu, V. Molecular Understanding of Organic Solar Cells: The Challenges. Acc. Chem. Res. 2009, 42, 1691-1699.

(37) Zhu, X.-Y.; Yang, Q.; Muntwiler, M. Charge-Transfer Excitons at Organic Semiconductor Surfaces and Interfaces. Acc. Chem. Res. 2009, 42, 1779-1787.

(38) Grancini, G.; Maiuri, M.; Fazzi, D.; Petrozza, A.; Egelhaaf, H.-J.; Brida, D.; Cerullo, G.; Lanzani, G. Hot Exciton Dissociation in Polymer Solar Cells. Nat. Mater. 2013, 12, 29-33.

(39) Jailaubekov, A. E.; Willard, A. P.; Tritsch, J. R.; Chan, W.-L.; Sai, N.; Gearba, R.; Kaake, L. G.; Williams, K. J.; Leung, K.; Rossky, P. J.; et al. Hot Charge-Transfer Excitons Set the Time Limit for Charge Separation at Donor/Acceptor Interfaces in Organic Photovoltaics. Nat. Mater. 2013, 12, 66-73.

(40) Devižis, A.; De Jonghe-Risse, J.; Hany, R.; Nüesch, F. A.; Jenatsch, S.; Gulbinas, V.; Moser, J.-E. Dissociation of Charge Transfer States and Carriers Separation in Bilayer Organic Solar Cells - A TimeResolved Electroabsorption Spectroscopy Study. J. Am. Chem. Soc. 2015, 137, 8192-8198.

(41) Gélinas, S.; Paré-Labrosse, O.; Brosseau, C.-N.; Albert-Seifried, S.; McNeill, C. R.; Kirov, K. R.; Howard, I. A.; Leonelli, R.; Friend, R. H.; Silva, C. The Binding Energy of Charge-Transfer Excitons Localized at Polymeric Semiconductor Heterojunctions. J. Phys. Chem. C 2011, 115, 7114-7119.

(42) Yoshikawa, H.; Adachi, S. Optical Constants of ZnO. Jpn. J. Appl. Phys. 1997, 36, 6237-6243.

(43) Němec, H.; Rochford, J.; Taratula, O.; Galoppini, E.; Kužel, P.; Polívka, T.; Yartsev, A.; Sundström, V. Influence of the ElectronCation Interaction on Electron Mobility in Dye-Sensitized $\mathrm{ZnO}$ and $\mathrm{TiO}_{2}$ Nanocrystals: A Study Using Ultrafast Terahertz Spectroscopy.

Phys. Rev. Lett. 2010, 104, 197401.

(44) Furube, A.; Katoh, R.; Yoshihara, T.; Hara, K.; Murata, S.; Arakawa, H.; Tachiya, M. Ultrafast Direct and Indirect ElectronInjection Processes in a Photoexcited Dye-Sensitized Nanocrystalline Zinc Oxide Film: The Importance of Exciplex Intermediates at the Surface. J. Phys. Chem. B 2004, 108, 12583-12592.

(45) Furube, A.; Katoh, R.; Hara, K.; Murata, S.; Arakawa, H.; Tachiya, M. Ultrafast Stepwise Electron Injection from Photoexcited $\mathrm{Ru}$-Complex into Nanocrystalline $\mathrm{ZnO}$ Film via Intermediates at the Surface. J. Phys. Chem. B 2003, 107, 4162-4166.

(46) Jin, F.; Tong, H.; Shen, L.; Wang, K.; Chu, P. K. MicroStructural and Dielectric Properties of Porous $\mathrm{TiO}_{2}$ Films Synthesized on Titanium Alloys by Micro-Arc Discharge Oxidization. Mater. Chem. Phys. 2006, 100, 31-33.

(47) Barzykin, A. V.; Tachiya, M. Mechanism of Molecular Control of Recombination Dynamics in Dye-Sensitized Nanocrystalline Semiconductor Films. J. Phys. Chem. B 2004, 108, 8385-8389.

(48) Katoh, R.; Furube, A.; Barzykin, A. V.; Arakawa, H.; Tachiya, M. Kinetics and Mechanism of Electron Injection and Charge Recombination in Dye-Sensitized Nanocrystalline Semiconductors. Coord. Chem. Rev. 2004, 248, 1195-1213.

(49) Kallioinen, J.; Benkö, G.; Sundström, V.; Korppi-Tommola, J. E. I.; Yartsev, A. P. Electron Transfer from the Singlet and Triplet Excited States of $\mathrm{Ru}(\mathrm{dcbpy})_{2}(\mathrm{NCS})_{2}$ into Nanocrystalline $\mathrm{TiO}_{2}$ Thin Films. J. Phys. Chem. B 2002, 106, 4396-4404.

(50) Benkö, G.; Kallioinen, J.; Myllyperkiö, P.; Trif, F.; KorppiTommola, J. E. I.; Yartsev, A. P.; Sundström, V. Interligand Electron Transfer Determines Triplet Excited State Electron Injection in RuN3-Sensitized $\mathrm{TiO}_{2}$ Films. J. Phys. Chem. B 2004, 108, 2862-2867.

(51) Rex, R.; Knorr, F. J.; McHale, J. L. Spectroelectrochemical Photoluminescence of Trap States of Nanocrystalline $\mathrm{TiO}_{2}$ in Aqueous Media. J. Phys. Chem. C 2014, 118, 16831-16841. 


\section{Supporting Information}

\section{Dynamics of Interfacial Charge Transfer States and Carriers Separation in Dye-Sensitized Solar Cells - A Time-Resolved THz Spectroscopy Study}

Jan C. Brauer, Arianna Marchioro, Arun A. Paraecattil, Ahmad A. Oskouei, and Jacques-E. Moser*

Photochemical Dynamics Group, Institute of Chemical Sciences and Engineering, and Lausanne Centre for Ultrafast Science (LACUS),

Ecole Polytechnique Fédérale de Lausanne, CH-1015 Lausanne, Switzerland

* Corresponding author

E-mail : je.moser@epfl.ch 


\section{Femtosecond transient absorption data treatment}

The extinction coefficients of all the species contributing to transient absorbance signals observed at the probe wavelength were determined and were used in a spectro-kinetic model to isolate the dynamics of the appearance of dye oxidized state $\mathrm{S}^{+}$and, hence, the kinetics of the charge injection from the excited state of the dye $S^{*}$ to the conduction band of $\mathrm{TiO}_{2}$ (Eq. 1)

$$
\mathrm{S}\left|\mathrm{TIO}_{2}+\mathrm{h} v \rightarrow \mathrm{S}^{*}\right| \mathrm{TiO}_{2} \rightarrow \mathrm{S}^{+} \mid \mathrm{TiO}_{2}+\mathrm{e}^{-} \mathrm{cb}\left(\mathrm{TiO}_{2}\right)
$$

The probe wavelength $\lambda_{\text {probe }}=840 \mathrm{~nm}$ was chosen in order to observe the oxidized state $\mathrm{S}^{+}$of the dye with minimal contribution from the excited state $\mathrm{S}^{*}$ (Figure S1).

$$
\mathrm{S}^{+}\left|\mathrm{TiO}_{2}+\mathrm{HTM} \rightarrow \mathrm{S}\right| \mathrm{TiO}_{2}+\mathrm{h}^{+}(\mathrm{HTM})
$$

In solid-state dye-sensitized solar cells, charge transfer to the hole transporting material (Eq. 2) is orders of magnitude faster than the dye regeneration by common redox mediator used in liquid electrolytes. The deconvolution of the dynamics of processes (1) and (2), therefore, is more critical. The procedure for the fitting of the femtosecond transient absorption signals is described in refs. 16 and 21.

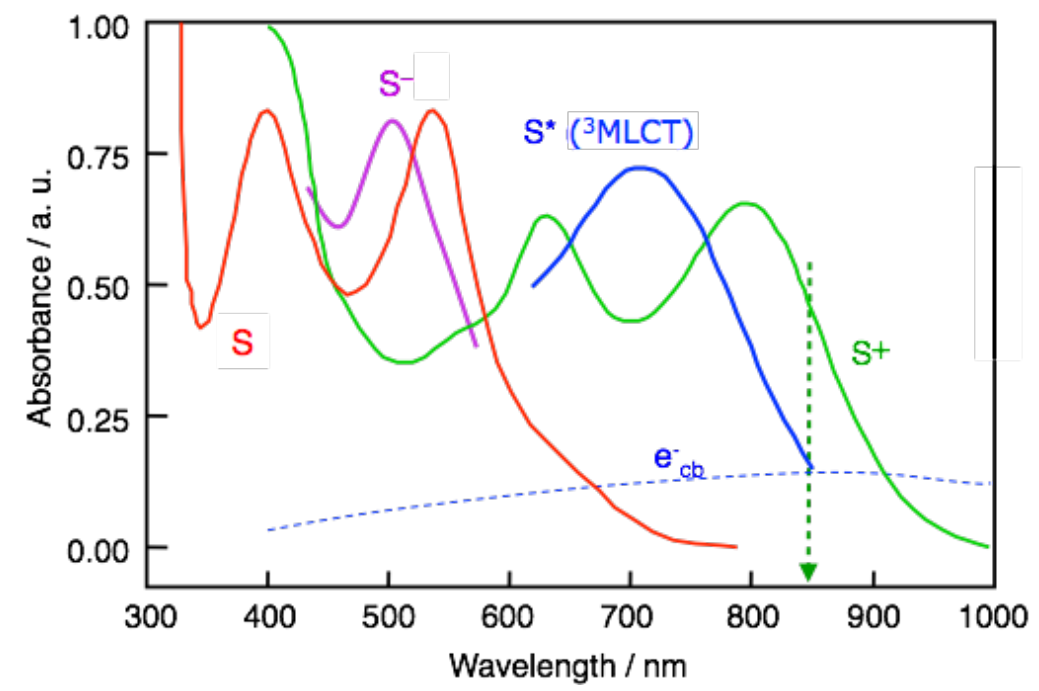

Figure S1. Relative absorbance spectra of the various species involved in the charge injection process according to the values of extinction coefficients determined in ref. 21. $\mathrm{S}$ represents here the amphiphilic $\mathrm{Ru}^{\mathrm{II}}$ complex dye Z907. Spectra of the parent dye complex N719 in comparable conditions is practically identical. The probe wavelength of $840 \mathrm{~nm}$ was selected, as it ensures the largest contribution to the absorbance signal of the $\mathrm{S}^{+}$species compared to $\mathrm{S}^{*}$ and $\mathrm{e}^{-} \mathrm{cb}$. 


\section{Confidence intervals of the fitting of transient absorbance data}

95\% confidence interval bands drawn here below in Figure S2 show that the fitting of noisy experimental points does not suffer much uncertainty and provides a clear picture of the time evolution of the transient absorbance monitored at $840 \mathrm{~nm}$.
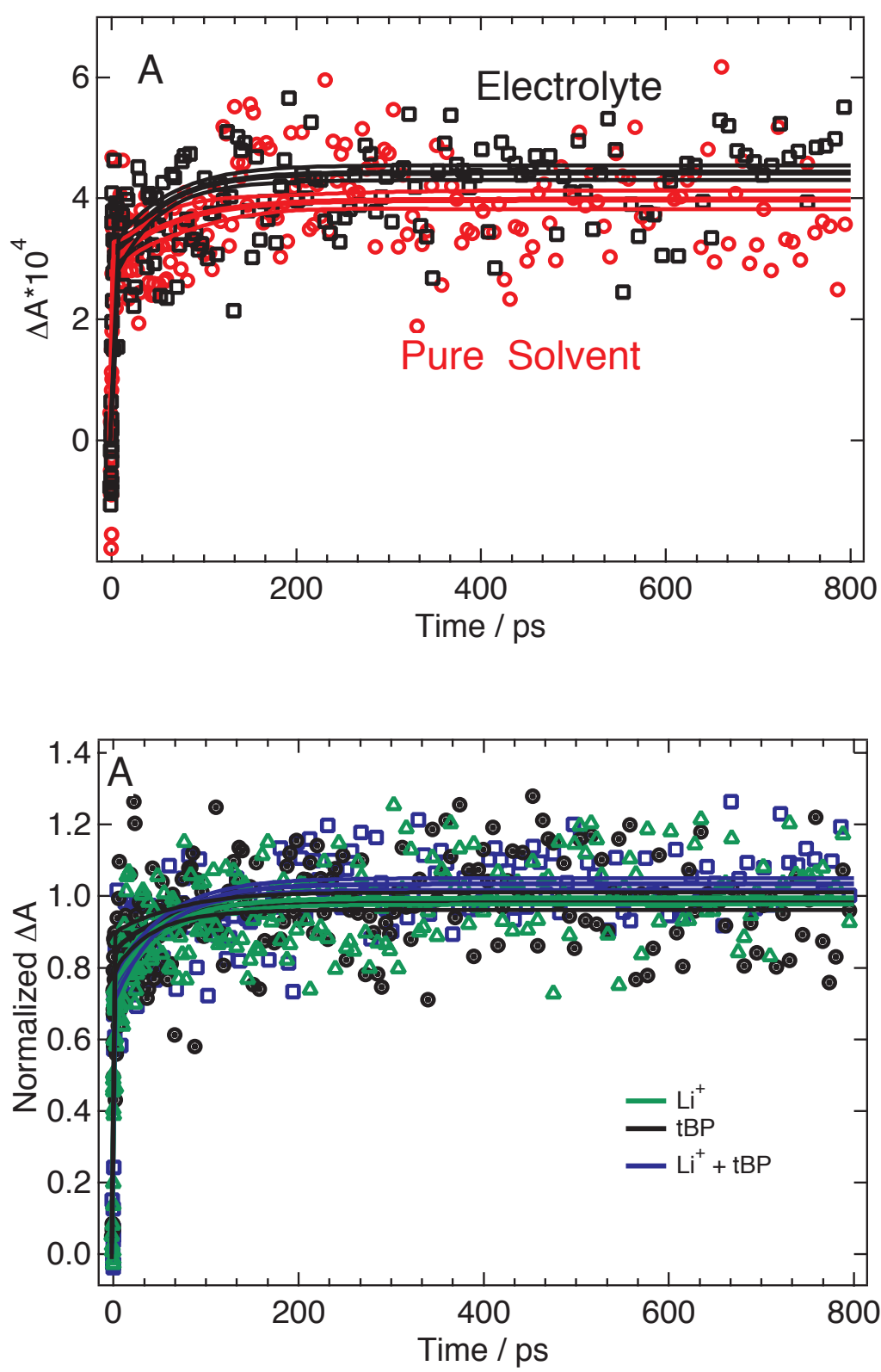

Figure S2. Experimental points reported in Figure 1A (top) and 2A (bottom). The limits of 95\% confidence intervals bands are added here on both sides of the fitting curves. 


\section{Contribution of holes in spiro-MeOTAD HTM to the THz absorption signal}

Blank measurements were performed on samples composed of mesoporous $\mathrm{Al}_{2} \mathrm{O}_{3} \mid \mathrm{Z} 907$ | spiro-MeOTAD (Figure S3). Fast hole transfer from Z907 excited state to the HTM along a reductive quenching pathway is expected to be quite effective in this case, where no electron injection into the oxide can take place. As we fail to observe any $\mathrm{THz}$ signal, we conclude that holes injected in the oxidized HTM, whose transport takes place through a hopping mechanism, are characterized by a negligible conductivity. This demonstrates that the transient photoconductivity signal recorded in solid-state dye-sensitized systems is not due to holes in the HTM but only to conduction band electrons in $\mathrm{TiO}_{2}$.

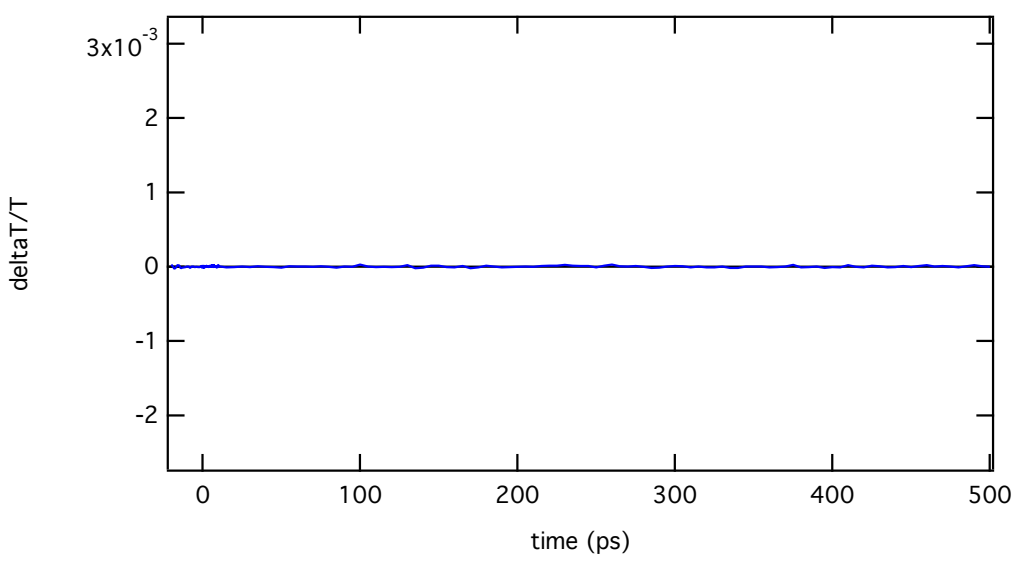

Figure S3. Transient THz transmittance change of a solid-state sample following fs laser pulse excitation at $\lambda_{\text {pump }}=590 \mathrm{~nm}$ of the amphiphilic ruthenium complex sensitizer cisRuLL'(SCN) 2 ( $\mathrm{L}=4,4^{\prime}$-dicarboxylic acid-2,2'-bipyridine, $\mathrm{L}^{\prime}=4,4^{\prime}$ - dinonyl-2,2'-bipyridine) adsorbed on a mesoporous $\mathrm{Al}_{2} \mathrm{O}_{3}$ film. The pores of the dyed nanocrystalline alumina scaffold were filled with pristine spiro-MeOTAD HTM by spin-coating. Other conditions are identical to those used to produce data of Figure 4B. 